\title{
The Review about Continuous Rigid Frame Bridge in Guizhou Mountain Area
}

\author{
Xing Zhang, Bin Du, Tao Wang \\ Guizhou University, Guiyang, China \\ Email: 469174844@qq.com
}

How to cite this paper: Zhang, X., Du, B. and Wang, T. (2016) The Review about Continuous Rigid Frame Bridge in Guizhou Mountain Area. Open Access Library Journal, 3: e3244.

http://dx.doi.org/10.4236/oalib.1103244

Received: November 21, 2016

Accepted: December 10, 2016

Published: December 13, 2016

Copyright $\odot 2016$ by authors and Open Access Library Inc.

This work is licensed under the Creative Commons Attribution International License (CC BY 4.0).

http://creativecommons.org/licenses/by/4.0/ (c) (i) Open Access

\begin{abstract}
Based on Guizhou mountain area, the characteristic of Guizhou mountain area and the characteristic of continuous rigid frame bridge were thought. An analysis about the advantage of this bridge type and the reason why this bridge type had energetic development in Guizhou mountain area was made. According to the collected literature and design information, the development status, including construction features, building materials, design theory and method, the key technique of construction and development prospect were revealed. Firstly, a review about the achievement of this bridge type in Guizhou mountain area was made. Then an induction and conclusion were given. In construction features, the parameter of bridge span and section was mainly introduced and a conclusion for the choice of this parameter was given. In materials, the characteristic and problem of present materials were analyzed, and then an outlook and advice for new materials, including lightweight and ultra high strength concrete and fiber reinforced composites, were given. In design, the method and key point in continuous rigid frame bridge design were reviewed; then mainly focusing on the durableness design, the limitation of the old bridge design specifications was concluded, and some ideas and an outlook were put forward for the new bridge design specifications. In construction, the construction method, the key step in construction, the common problems and solution were focused on. And the method, the affect and value of construction control in continuous rigid frame bridge were then simply introduced. In the end, the development of continuous rigid frame bridge is looking forward the future. This paper is expecting making some contribution for bridge construction in Guizhou mountain area and offering some basic information for beginners in bridge engineering.
\end{abstract}

\section{Subject Areas}

Civil Engineering 


\section{Keywords}

Guizhou Mountain Area, Continuous Rigid Frame Bridge, Construction Features, Design Method, Key Technique of Construction

\section{1. 概述}

\section{1. 贵州省连续刚构桥成果回顾}

连续刚构桥是由桥跨结构和墩台整体固结的连续梁桥。上部结构由 0 号梁段和 悬臂梁组成, 下部结构包括桥墩、桥台等基本构件。连续刚构桥在受力上以主梁受 弯矩作用为主, 在坚向荷载作用下, 主墩除了承受压力, 还要承受弯矩。连续刚构 桥具有以下优点: 桥梁外观尺寸小, 桥下净空大, 跨越能力强, 混凝土用量少; 施 工技术成熟, 施工场地要求低, 施工中无体系转换, 墩梁固结能显著减少墩顶负弯 矩和跨中正弯矩; 成桥后整体性好, 抗震性好; 行车平顺, 后期维护成本低。连续 钢构桥进入贵州, 要追溯到上世纪八十年代, 经过约 30 年的发展, 贵州已经有上百 座连续刚构桥建成, 特别是近 10 年来, 随着省内多座大跨度连续刚构桥的建成通车: 2001 年建成的主跨 $240 \mathrm{~m}$ 的贵毕公路六广河大桥; 2013 年建成通车的主跨 $290 \mathrm{~m}$ 的水盘高速公路北盘江特大桥, 是目前国内跨径最大的混凝土连续刚构桥; 2013 年 建成通车的毕威高速公路赫章大桥, 最大墩高 $195 \mathrm{~m}$, 位居世界同类桥梁之最。这 些成果标志着我省的连续刚构桥梁建造技术已经跃居世界先进水平。

\section{2. 连续刚构桥与贵州}

连续刚构桥在贵州省取得快速发展, 背后有其深层次的原因。贵州省地处云贵 高原东侧, 是一个被四川盆地, 广西丘陵和湖南丘陵包围的山岭重丘区, 是全国唯 一一个没有平原支撑的省份, 境内地形起伏大, 有 “地无三里平” 的说法[1]。桥梁 多跨越 “ $V$ ” 型或 “ $U$ ” 型峡谷, 两岸多为悬崖峭壁。境内喀斯特地貌分布极广, 溶岩带, 裂隙带分布广, 另外, 贵州省又是一个受石漠化灾害较重的省份, 深谷两 岸的岩层多裸露在外, 风化程度严重, 风化层较厚。贵州省境内水路运输资源稀缺, 桥跨两岸施工便道运输能力差, 建桥材料和构件运输困难。施工场地狭小, 桥梁施 工难度大。以上种种因素, 限制了贵州省内桥型选择的范围。在这样的背景下, 连 续刚构桥由于采用挂篮悬臂浇筑施工, 施工场地要求低, 成桥后整体性好, 跨越能 力强, 运营成本低, 耐久性好的优点得到充分发挥, 使得连续刚构桥成为贵州省大 跨度桥梁建设中强有力的竞争者。表 1 是贵州省 21 世纪建设的大跨度预应力混凝土 连续刚构桥设计参数统计表。

\section{2. 总体布置和结构构造}

\section{1. 跨径组成}

\subsection{1. 连续刚构桥联长选择}

连续刚构桥的总体布置一般从受力合理和经济合理的角度考虑, 常见形式有 
表 1. 贵州省 21 世纪建设的大跨度预应力混凝土连续刚构桥设计参数统计表

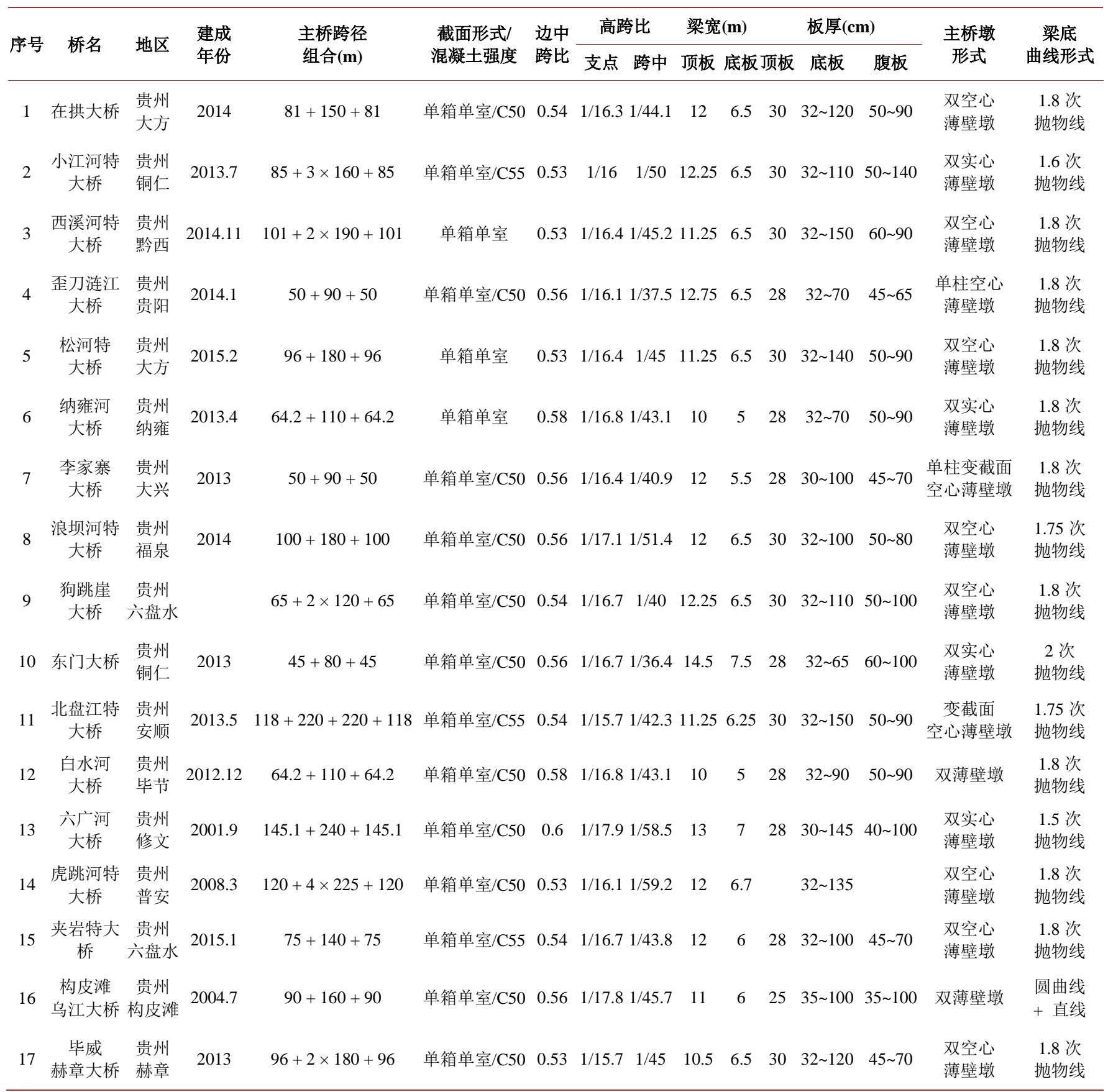

三跨连续刚构桥、多跨连续刚构桥等。为减少次应力对连续刚构桥结构的影响, 连 续刚构桥的联长不宜过长; 同时桥墩高度的选择, 也会影响内力分布和全桥的经济 性。一般情况下, 连续刚构桥的联长与桥墩存在以下关系:

$$
\sum l \leq 7 H
$$

$H$-一为离滑动支座最近桥墩的高度。

若超过这一范围, 可将次边墩的墩梁固结释放, 形成刚构 - 连续组合梁桥。 


\subsection{2. 边跨比}

连续刚构桥的边、中跨跨径的比例会影响桥梁的内力分布和预应力钢束的布置, 从国内外已建成的桥梁来看, 边跨比一般在 $0.5 \sim 0.7$ 之间, 大部分保持在 $0.54 \sim 0.58$ 之间, 特别地, 当边跨比为 $0.54 \sim 0.56$ 时, 进行边跨合拢施工时, 可取消边跨合拢 段的落地支架，以达到使施工方便、经济的目的。

\subsection{3. 特殊的桥跨布置形式}

当遇到地形或其他条件限制时, 连续刚构桥的边主跨比会小于 0.5 , 形成小边跨、 不对称的连续刚构桥, 比如贵州的落拉河大桥以及岩头河大桥, 这种形式对桥墩和 主梁的受力是不利的, 为了消除这种不利影响, 通常采用边跨与基础针碇或采用大、 小 $T$ 的方法, 以达到平衡、协调负反力的目的, 但是应控制不对称系数 $\eta$ 在 $0.4 \leq \eta<1$ 的合理区间[2]内, 以避免系统温差、收缩、徐变、基础沉降等对内力分布造成的影 响以及主梁应力恶化, 难以满足规范要求。

\section{2. 截面构造}

\subsection{1. 截面形式}

相比 $T$ 形截面, 箱型截面具有更好的抗弯刚度和抗扭刚度。连续刚构桥在悬臂 施工时, 对主梁的抗扭刚度要求较高, 在成桥后主梁以受弯为主, 综合以上原因, 主梁多采用抗弯能力和抗扭能力更好的箱梁。箱梁截面有单箱单室, 单箱双室, 单 箱多室等多种。单箱单室截面具有整体性好, 受力明确, 且施工方便, 材料用量小 等优点, 但是桥面板和悬臂长度不宜过大。单箱双室、单箱多室截面由于腹板的增 加, 能有效降低主拉应力和剪应力, 同时有足够的空间布置预应力钢束。但单箱多 室截面施工难度大, 自重弯矩比重大等缺点, 限制了单箱多室截面的应用。根据统 计资料表明, 目前国内外, 对于顶板宽度在 $20 \mathrm{~m}$ 以下时, 基本都采用单箱单室截 面, 当顶板宽度更大时, 往往采用上、下行分离的设计, 修成双幅桥, 截面为两个 分离的单箱单室箱[3]。

\subsection{2. 顶板宽度}

根据收集的资料, 当采用单箱单室截面时, 顶板宽度主要在 $10 \sim 20$ 米的范围, 贵州省内则主要集中在 $10 \sim 13$ 米的范围, 这与我省公路设计车道数较少有一定关系。

\subsection{3. 高跨比}

连续刚构桥一般采用变截面箱梁, 箱梁根部梁高的高跨比一般在 $1 / 15 \sim 1 / 20$ 之 间, 大部分在 $1 / 17$ 左右, 跨中梁高的高跨比一般在 $1 / 54 \sim 1 / 60$ 之间, 但是不宜小于 $2.5 \mathrm{~m}$ 。与连续梁 $(1 / 30 \sim 1 / 50)$ 相比, 连续刚构桥的跨中梁高较小, 原因在于连续刚 构桥是墩梁固结体系, 降低跨中内力水平, 跨中正弯矩较连续梁小, 这也是连续刚 构桥比连续梁具有更大的跨越能力的主要原因。

图 1、图 2 分别反映的是墩顶梁高、跨中梁高与主跨径的关系。从图 1 中可以 看出, 墩顶梁高与主跨跨径的呈线性关系, 拟合方程为: $h=0.0511 L+1.0214$, 相 关系数为 $R^{2}=0.9291$, 线性关联程度高; 从图 2 可以看出跨中梁高与主跨径之间也 存在一定的线性关系, 拟合方程为: $h=0.0094 L+1.7984$, 但是相关系数仅为 $R^{2}=0.5512$, 不及墩顶梁高与主跨径的关联程度高。 


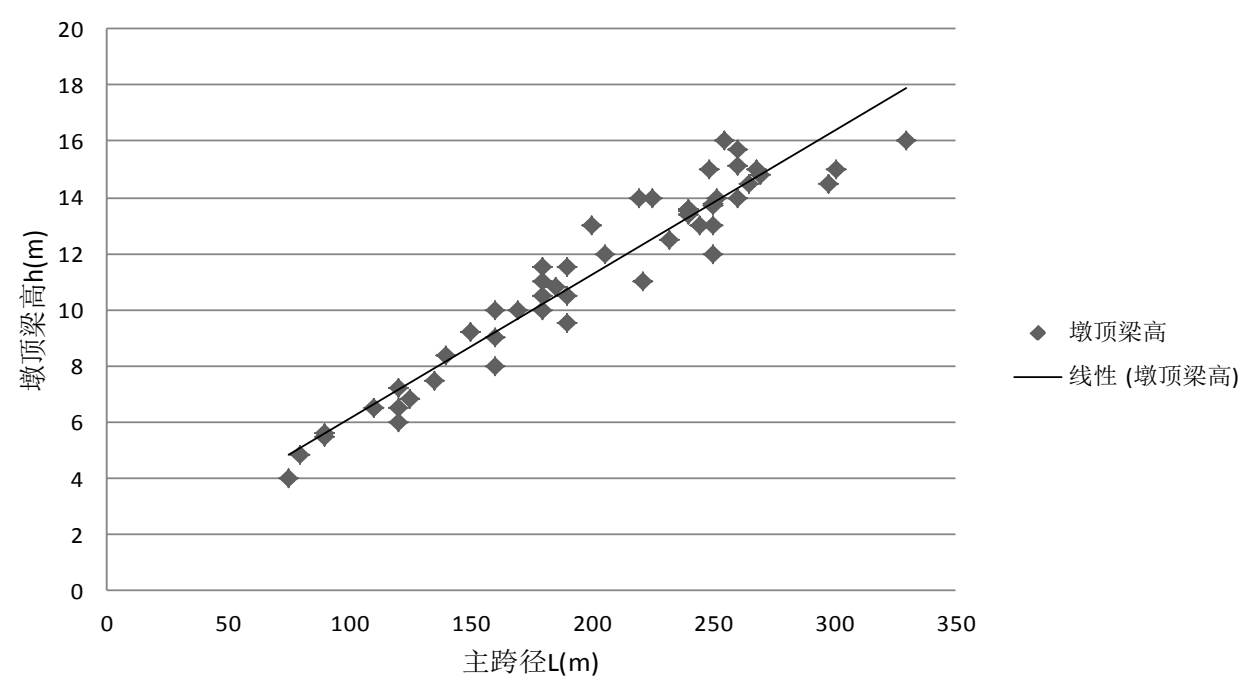

图 1. 墩顶梁高与主跨径的关系

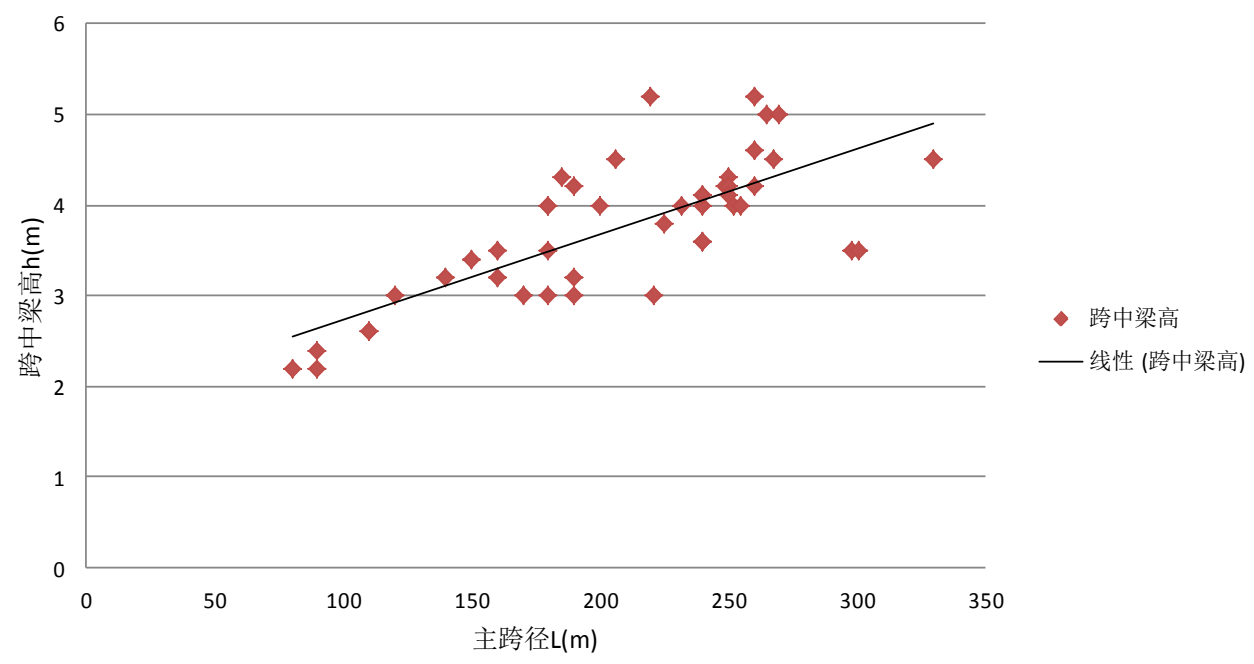

图 2. 跨中梁高与主跨径的关系

\subsection{4. 梁底变化形式}

箱梁底部的变高度曲线常见的有二次抛物线、正弦曲线和半立方曲线。目前广 泛应用的是按抛物线变化, 在跨径较大时, 采用 2 次抛物线会导致部分区段的梁高 不足, 此时宜采用 $1.5 \sim 1.8$ 次抛物线变化 [4]。但是随着底板曲线次数的降低, 底板 局部应力呈增大趋势 [5], 若超过混凝土极限抗拉强度, 易导致底板混凝土崩裂等问 题, 必要时要采取相应的构造措施, 如设置底板横向加劲肋或设置横隔板等。

\subsection{5. 顶、底板和腹板厚度}

箱梁的顶、底板是结构承受正负弯矩的主要工作部分。其厚度选择主要考虑桥 面板的横向受力、布置纵向预应力钢束所需要的空间、承受施工荷载等因素。通常 情况下, 顶板的厚度不宜小于 $25 \mathrm{~cm}, 0$ 号梁段和边跨合拢段要做适当加厚; 箱梁 根部底板的厚度一般去梁高的 $1 / 10 \sim 1 / 12$, 跨中的底板厚度一般可取 $25 \sim 30 \mathrm{~cm}$ 。从 根部到跨中, 底板厚度顺桥向变化应该保持在一条平滑的曲线上。 
腹板的主要作用是抵抗扭矩、剪力及为预应力钢束提供空间并分散预应力荷载, 避免局部应力集中。腹板的厚度一般不宜小于 $40 \mathrm{~cm}$, 箱梁根部根据需要可加厚到 $100 \mathrm{~cm}$, 大跨径连续刚构桥腹板多采用变厚度腹板设计, 中、小跨径的则可以采用 等厚度腹板设计, 以方便施工。

连续刚构桥的跨径与各板厚之间的关系如图 3 所示。从图中, 可以看出, 除箱 梁根部底板厚度与主跨径具有较高关联度 $\left(\right.$ 相关性系数 $\left.R^{2}=0.6723\right)$ 外, 其余各部分 板厚与主跨径的并不直接相关。据此推测, 决定各部分板厚的因素是: 1) 预应力束 所需空间；2）施工荷载的大小；3）应力集度。

\subsection{6. 桥墩形式和尺寸}

\section{(1) 桥墩形式的选择}

连续刚构桥在运营阶段存在水平推力, 因此要求桥墩具有较小的纵向抗推刚度, 使全桥成为一个摆动体系以消除水平推力的不利影响。同时对于桥墩自身, 又要满 足强度、刚度及稳定性的要求。常见的桥墩形式有单肢薄壁墩、双肢薄壁墩、 $V$ 型 墩、 $Y$ 型墩等。单肢薄壁墩抗扭刚度大, 抗推刚度较大, 随着高度增加, 柔性逐渐 增强, 适用于墩身很高的大跨连续刚构桥; 双肢薄壁墩抗推刚度小, 允许的顺桥向 水平位移大, 能够很好适应上部结构的变形, 可以起到削减墩顶负弯矩的峰值的作 用, 从而减小墩顶截面尺寸, 在高墩大跨连续刚构桥中得到广泛使用; $V$ 型或 $Y$ 型 墩是结合斜腿刚构和双肢薄壁墩的特点而产生的桥墩形式, 能起到缩短跨径、减小 主梁高度、使结构显得轻巧美观的作用, 多用于城市跨线桥或风景区公路修建的连 续刚构桥。空心式桥墩是桥墩机械化施工发展的方向。空心式桥墩可以节省材料, 降低自重, 降低地基要求, 力学性能好, 在高墩中优势尤其明显。目前亚洲最高的 空心式桥墩就出自贵州省内毕威高速公路的赫章大桥, 高达 $195 \mathrm{~m}$ 。在贵州省内, 由于地形特点, 高桥墩情况较多, 我省 $60 \mathrm{~m}$ 以上的高桥墩绝大多数是空心墩[6]。

\section{(2) 桥墩构造尺寸}

对于连续刚构桥桥墩尺寸的拟定, 应考虑桥墩合理刚度、桥墩整体安全系数、 桥墩传力受力情况等方面, 可按下列方法拟定尺寸:

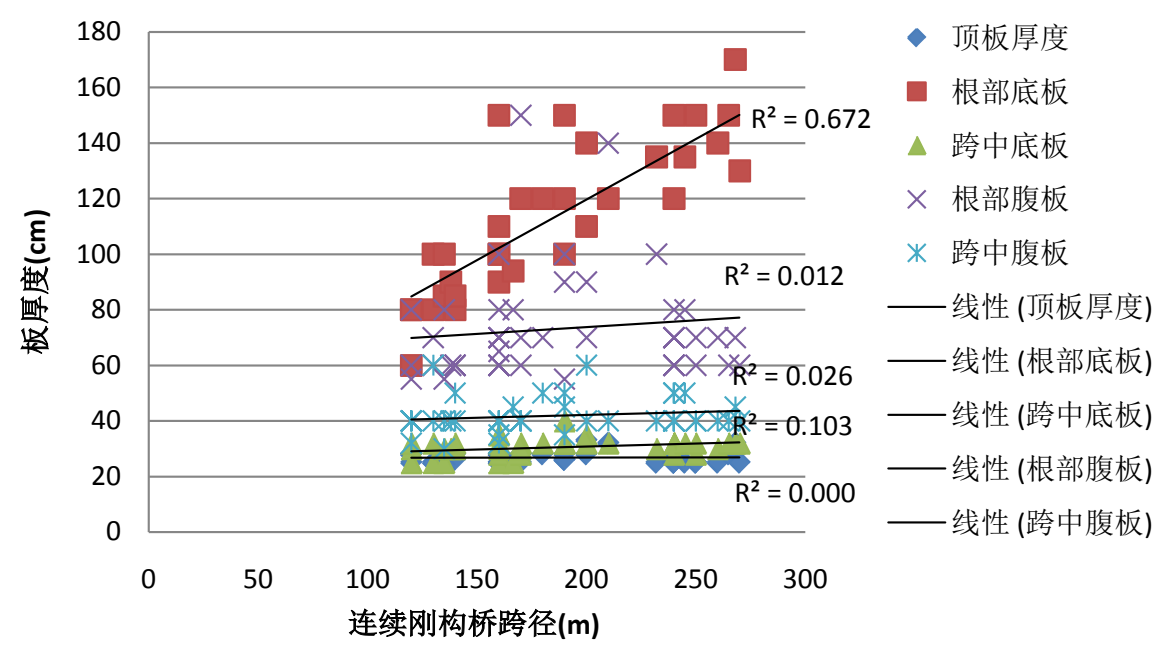

图 3. 主跨径与各板厚的关系 
1) 设横桥向桥墩为宽度 $a_{1}$, 箱梁底板宽度为 $a_{0}$, 一般取 $a_{1}=a_{0}$; 当桥墩较高 或箱梁底板过小时, 出于稳定性方面的考虑。可使 $\left(a_{1}-a_{0}\right) \in[150 \mathrm{~cm}, 250 \mathrm{~cm}]$ 。

2) 顺桥向壁厚 $b$ 和双肢间距 $d$ (若采用双肢薄壁墩)对桥墩受力和稳定性有直 接影响; $b$ 值减小, 桥墩整体稳定性下降, 桥墩所受弯矩、轴力减少; $d$ 值减小, 桥墩整体稳定性下降, 桥墩所受弯矩减小, 所受轴力增大, 反之亦然。

3) 顺桥向桥墩壁厚 $b$ 的尺寸, 要考虑桥墩的合理刚度, 目的在于使主墩刚度在 使用阶段能满足顺桥向的所需的水平位移, 在施工阶段桥墩刚度能够抵抗施工阶段 的不平衡弯矩。根据文献[7], 由于温度变化位移最大, 因此可根据温度变化位移来 确定壁厚 $b$ :

设横桥向墩外宽为 $a$, 内宽为 $a^{\prime}$, 顺桥向外厚 $b$, 内厚 $b^{\prime}$, 当 $a^{\prime}=0, b^{\prime}=0$ 时为 实心墩;

根据温度变化与墩顶水平力的关系有: $\delta=\alpha \Delta T \frac{1}{2} L=\frac{P H^{3}}{3 E I}=\frac{2 P H^{3}}{E\left(a b^{3}-a^{\prime} b^{\prime 3}\right)} 。$

根据以上关系结合工程经验取 $a-a^{\prime}=100 \mathrm{~cm}, b-b^{\prime}=100 \mathrm{~cm}$ 代入, 即可确定合 理壁厚 $b$ 。

4) 若采用双肢薄壁墩, 根据施工中出现的不平衡弯矩, 按以下方法确定: 施工阶段受到的不平衡弯矩应满足: $\frac{\Delta M}{W} \leq 1.15 f_{t}$ or $0.7 f_{t}$ (预应力区不配置普通钢 筋时, 取小值);

此时的抗弯截面刚度 $W=\frac{I_{b}}{\frac{b}{2}+\frac{d}{2}}$, 双肢薄壁截面惯性矩 $I_{b}=2\left[\frac{a b^{3}}{12}-\frac{a^{\prime} b^{\prime 3}}{12}+\left(a b-a^{\prime} b^{\prime}\right)\left(\frac{d}{2}\right)^{2}\right]$, 据此可确定双肢薄壁墩的间距 $d$ 。

5) 在空心薄壁墩中, 应在上下两端设置一定长度的实心区段, 考虑高墩刚度和 稳定性, 以及有利于传力和与承台连接, 空心墩底应设置 $2.5 \sim 3 \mathrm{~m}$ 的实心段。

6) 空心墩顶部承受上部结构传来的巨大集中力, 为了使应力通过墩身很好传递 到基础且避免应力集中造成局部受力不利, 应设置实体过渡段, 根据文献[8]的规定, 在空心墩两端应设置 $1.0 \sim 2.0 \mathrm{~m}$ 的实心过渡段。

\section{3. 新型建筑材料}

\section{1. 混凝土}

\subsection{1. 普通混凝土的应用}

我国于 1988 年建成我国首座连续刚构桥一一广东番禹洛溪大桥, 该桥主桥采用 C50 混凝土, 此后, 我国建造连续刚构桥采用的混凝土等级虽有提升, 但幅度不大, 主要集中在 $C 50 \sim C 60$ 之间。随着跨径增大, 使用普通混凝土建造的连续刚构桥存 在自重过大、主跨过度下挠和梁体开裂的问题, 若继续使用传统的普通混凝土将极 大的限制连续钢构桥的承载能力、跨越能力以及耐久性。

\subsection{2. 超高性能混凝土的使用前景}

长久以往, 有关于超高性能混凝土(UHPC) 研究和制作工艺的滞后, 极大的限 
制了我国连续刚构桥的跨越能力。采用超高强度的高性能混凝土可降低箱梁自重 40\% 50\%, 结构上部结构自重比重下降, 跨越能力和承载能力得到提升。根据彭 元诚[6]等人的研究, 采用 $C 100$ 以上级别的超高性能混凝土, 可以将连续刚构桥的 跨越能力提高到 $300 \mathrm{~m}$ 以上。并因强度高、徐变小, 可以降低传统大跨径 PC 混凝 土连续刚构桥跨中下挠严重和梁体开裂的风险。目前对于 UHPC 在连续刚构桥上的 应用, 仍处于实验室阶段, 虽然通过试验分析证明采用 UHPC 对于提高连续刚构桥 的跨越能力和综合性能具有显著效果, 但是应用于工程实践, 还需解决 UHPC 造成 的构件薄壁化后的局部稳定及预应力锚固等问题[9]。

\subsection{3. 轻质混凝土的应用}

采用轻质混凝土, 目的在于降低上部结构自重以提高桥梁跨越能力, 根据连续 刚构桥的受力特点, 在跨中区段采用轻质混凝土, 对提高桥梁的跨越能力, 有显著 效果。如挪威 Stolma 桥和 Raftsundet 桥在跨中主梁分别采用 $182 \mathrm{~m}$ 和 $224 \mathrm{~m}$ 的轻质 混凝土, 使得主跨径分别达到了 $301 \mathrm{~m}$ 和 $298 \mathrm{~m}$ 的跨径, 这也是连续刚构桥的跨越 能力首次突破 $300 \mathrm{~m}$ 。目前国内关于轻质混凝土在连续刚构桥上的应用尚未有报道, 但是根据文献[10] [11]对轻质混凝土性能的研究, 轻质混凝土由于具有与普通混凝 土类似的收缩徐变特性, 文献[12]显示, 挪威 Stolma 桥在成桥三年后, 跨中下挠达 $92 \mathrm{~mm}$ 。据此推测, 轻质混凝土应用于连续刚构桥仍需要解决因收缩徐变造成的预 应力损失问题和跨中持续下挠的问题。

\subsection{4. 钢 - 混组合材料}

虽然轻质混凝土对于提高梁桥的跨越能力具有突出贡献, 但是轻质混凝土的骨 料材料稀少, 材料单价高, 综合经济性有待论证。钢 - 混组合材料具有自重轻, 抗 震性好, 刚度大的特点, 有助于提高桥梁跨越能力, 减少跨中挠度。2006 年建成的 重庆石板坡长江大桥复线桥在跨中采用了 $108 \mathrm{~m}$ 长的钢箱梁, 使得全桥的跨越能力 达到了 $330 \mathrm{~m}$, 一举成为世界第一的连续刚构桥。但是刚 - 混组合材料在结合处的 构造复杂, 传力机理的研究还有待深入。

未来, 推进超高强度混凝土的商品化应用, 提高轻质混凝土综合性能及对钢 混凝土组合材料的构造及传力机理的深入研究, 对提高连续刚构桥的承载能力、跨 越能力以及耐久性具有十分重要的作用和意义。

\section{2. 预应力筋材料}

预应力筋是连续刚构桥的主要承重材料, 主要制作材料是钢材, 主要形式有: 高强度预应力钢绞线、高强钢丝、精轧螺纹钢等, 预计未来 10 15 年由钢材制成的 预应力筋仍是主要的预应力材料。非金属预应力材料主要是纤维增强复合材料, 有 玻璃纤维、碳纤维、芳纶纤维等, 属于新型预应力材料的范畴。

\subsection{1. 预应力钢绞线}

低松弛预应力钢绞线是具有优良的性能和良好的经济性, 是目前全球最广泛采 用的预应力材料。在连续刚构桥中主要是用作纵、横向预应力筋。在桥梁工程领域 常见的规格有 2 股、3 股和 7 股一束等几种规格，目前主要采用的是 7 股 1 束的直 
径 $\phi 15.2$ 的钢绞线, 强度级别达到 $1860 \mathrm{MPa}$ 以上。另外为了满足更高的抗腐蚀性的 要求, 在此基础上还发展出了无粘结钢绞线、镀锌钢绞线和环氧树脂钢绞线等。

\subsection{2. 精轧螺纹钢}

在连续刚构桥中, 为避免箱梁腹板开裂, 需要施加坚向预应力, 此时使用的预 应力筋就是精轧螺纹钢, 精轧螺纹钢是一种热轧而成的无纵肋的直条钢筋, 可以在 任意截面用螺纹套筒进行接长。直径在 $10 \sim 40 \mathrm{~mm}$, 屈服强度 $540 \sim 930 \mathrm{MPa}$, 目 前这种材料作为坚向预应力材料存在的主要缺陷是钢筋张拉长度短, 针具变形和钢 筋回缩量大, 预应力损失大, 损失量可达 $40 \sim 50 \%$, 所带来的直接影响是削弱了腹 板的抗剪能力, 造成腹板开裂情况严重, 削弱结构刚度, 造成跨中下挠持续加深。 根据张阳、郡旭东[13]等人的研究, 由于高强钢绞线相比精轧螺纹钢具有较好的二 次张拉性能, 采用高强度钢绞线, 采用二次张拉工艺, 代替精轧螺纹钢做竖向预应 力材料, 可以将预应力损失控制在 $10 \%$ 以内, 可有效提高坚向应力的效率和腹板的 抗剪可靠性。据此, 精轧螺纹钢作坚向预应力材料有被高强钢绞线取代的趋势。

\subsection{3. 纤维增强复合材料}

纤维增强复合材料(FRP)是由包裹在树脂中的连续纤维形成的一种新型复合材 料, 纤维起加劲作用, 素树脂的主要作用是粘结纤维的作用。根据纤维的不同, 可 分为碳纤维复合材料(CFRP)、玻璃纤维复合材料(GFRP)及芳纶纤维复合材料(AFRP) 等三大类。其中最常见的是 CFRP, 这归功于碳纤维比强度高, 抗拉强度高, 弹性 模量大, 自重轻, 抗腐蚀能力强, 抗疲劳性能优良, 热膨胀系数低, 温度应力小, 应力 - 应变关系呈线弹性, 是一种理想的建筑材料, 具有代替预应力钢材的潜质, 但是我国对于纤维增强复合材料的研究起步较晚, 核心技术主要掌握在美、日等发 达国家, 材料使用成本高。目前, CFRP 材料主要用于桥梁加固方面, 以受力筋的 形式用作新桥建造材料仍需解决这几点问题[14]:

1) CFRP 材料抗剪强度较低;

2) CFRP 筋与钢材相比弹性模量仍然较低;

3) 适用 CFRP 筋的针固系统的针固机理、内部的荷载传递机理、针固系统的静 力、动力响应等方面的研究不够充分, 还有待进一步的深入研究。

\subsection{4. 张拉针固体系}

在洛溪大桥建设之前, 我国的预应力发展水平低, 张拉吨位小, 预应力损失大, 效率低, 使得变截面连续梁桥的跨径很难突破 $150 \mathrm{~m}$, 洛溪大桥首次引入大吨位预 应力体系, 使梁式桥的跨径达到了 $180 \mathrm{~m}$, 同时也推动了我国预应力技术的发展, 目前我国的预应力张拉吨位已突破 $1000 \mathrm{t}$, 效率高, 预应力钢绞线工厂化生产的强 度等级达 $1860 \mathrm{Mpa}$, 自主研发的 YM 和 OVM 针固体系也摆脱了针固技术长期依赖 国外的状况, 我国的预应力张拉针固体系已经达到了世界先进水平[15]。

随着预应力设计计算理论的不断完善, 预应力材料的不断发展, 以及施工工艺 的不断成熟, 预应力技术的应用将走向标准化、普遍化的方向。就连续刚构桥这种 桥型而言, 预应力材料与预应力技术研究的不断深入, 使得连续刚构桥的理论跨径 达到 $350 \mathrm{~m}$, 在一定程度上, 已具备与混凝土斜拉桥竞争的实力。 


\section{4. 设计分析}

\section{1. 设计思路}

在确定连续刚构桥方案进行设计时, 要明确以下几点: 桥梁的三维特征参数, 所处线路等级, 线型参数, 设计荷载等级参数, 建桥材料参数, 施工方案和现行规 范等[16]。参考已建成的同类型的桥梁拟定细部尺寸后, 对拟定的结构进行内力分 析后估算预应力钢束的面积, 并按照划分的施工阶段布置钢束, 再进行验算, 对于 不满足和不合理的情况进行调整, 遵循 “设计, 校核, 修改, 再校核” 的思路[16], 反复几次, 直到满足现行规范要求和达到最佳合理的工作状态为止 [3]。连续刚构桥 是超静定结构, 设计分析时要充分考虑预应力、墩台基础变位、温度、混凝土收缩 徐变等对结构的影响。对这种桥型设计分析包括配筋设计, 整体静力分析、横向受 力分析、地震动力响应分析以及稳定性分析等几个方面。

\section{2. 静力分析的主要内容}

连续刚构桥的静力分析应将全桥上部结构和下部结构作为共同受力的整体, 进 行整体分析计算。对于各部分的分析, 应遵从现行 《公路桥涵设计通用规范》 (JTG D60-2015) 的规定, 考虑两种极限状态, 取三种作用组合中最不利组合效应进 行设计分析。在截面配筋设计和验算时, 均应该满足现行《公路钢筋混凝土及预应 力混凝土桥涵设计规范》(JTG D62-2004) 中各项指标的规定。

\section{3. 分析方法}

连续刚构桥的分析方法主要分为平面杆系法和空间有限单元法。

\subsection{1. 平面杆系分析法的局限}

过去受限于计算机性能以及早期的桥梁宽度较小, 所以通常用平面杆系简化桥 梁实际结构进行分析, 这种方法具有模型受力明确, 计算方法简单的特点, 但是这 种分析方法不能反映箱梁的 “剪力滞效应” ; 不能反映横向挠曲; 对于薄壁箱梁的 扭转和畸变效应也仅仅是采用经验放大系数来进行考虑。对于早期宽度小、荷载等 级低的桥梁尚能满足工程精度的要求。但是随着桥梁宽度增加荷载等级的提升, 仅 采用平面杆系法进行桥梁结构分析不能较准确的反应结构实际的受力状态, 即使验 算通过, 也会因为与实际情况存在偏差对桥梁结构在使用阶段带来难以预料的问题 [12]。

\subsection{2. 有限单元法的使用}

为了克服平面杆系分析法的缺陷, 可采用空间有限元法进行分析, 根据离散单 元属性的不同, 可以分成不同的有限元法: 梁单元法、梁格法、板壳单元法、三维 实体单元法等。采用空间有限元法分析结构, 在建模精度得到保证的情况下, 能很 好的反应实际结构的受力情况; 特别是采用后三种方法能较好的反应箱梁的空间效 应; 对于像 0 号块这样受力复杂的构件进行局部受力分析。但是有限元法建模较复 杂, 计算量大, 计算精度常常依赖设计人员对结构的理解程度, 计算速度受限于计 算机性能。目前仍主要利用空间梁单元简化全桥实际结构进行分析计算, 必要时再 
辅以空间三维模型进行分析的方法。这种方法缺点在于：低自由度的空间梁单元不 能考虑空间效应而低估主拉应力, 很多大跨径连续刚构桥腹板出现较多斜裂缝也与 此有关; 高自由度空间梁单元虽然能反应箱梁的空间效应, 但计算量大, 当桥梁宽 度大, 会因为桥梁截面不在满足平截面假定而出现较大偏差。对于大跨径连续刚构 桥, 在一定宽度范围内, 这种方法仍具有实用价值。三维实体单元法优点适用性广, 可以用来模拟任意复杂的结构, 对于箱梁的空间效应能够进行全面的考虑; 缺点是 分析结果不能直接用来根据现有规范进行配筋设计, 工程实用性较差。目前, 三维 实体单元法主要用来进行局部受力分析。随着计算机和有限元技术的发展以及大型 的结构分析软件的不断成熟, 三维实体单元法的工程实用性有望得到提升, 优势将 得以彰显。表 2 是几种主要分析方法的比较。

\section{4. 设计荷载}

\subsection{1. 设计荷载的选取}

山区连续刚构桥多采用挂篮悬臂浇筑法进行施工, 在设计时, 要综合考虑施工 机械、施工周期, 温度效应等因素进行恰当的施工节段划分。山区连续刚构桥考虑 的荷载作用包括结构自重、施工荷载、收缩徐变作用、预应力一次效应及次内力、 活载、温度效应和风荷载。除风荷载外, 其他几种荷载作用可根据设计资料参考现 行设计规范取用。

\subsection{2. 风荷载对结构的影响}

风荷载对连续刚构桥的影响主要是静力作用, 包括 3 个方面: 内力和变形、扭 转发散、横向屈曲。对于平坦区域的刚构桥可以参考现行的公路桥梁抗风合计规范 的相关规定进行计算。但是对于山区, 地貌变化多, 风场分布复杂, 现行的桥梁抗 风规范的规定值与现实情况将存在一定的差异[17]。针对山区的这种情况, 应该综 合考虑桥址区的地形、地貌和风向, 采用现场实测的方法对规范规定值进行修正 [6]。 特别是在当施工到最大悬臂状态时, 由于桥墩刚度较低, 对风荷载特别敏感, 风荷 载在此阶段很大程度上起到了控制荷载作用, 最大双悬臂施工阶段也是连续刚构桥 的抗风控制状态, 因此对高墩大跨连续刚构桥在最大悬臂状态的抖振响应的研究对 于山区连续刚构桥设计来说显得尤为重要[18]。

表 2. 主要分析方法比较

\begin{tabular}{|c|c|c|c|c|c|c|c|c|c|}
\hline & 箱梁计算方法 & 纵向弯曲 & 自由扭转 & 约束扭转趐曲 & 畸变扭转 & 畸变横向挠曲 & 剪力滞 & 横向弯曲 & 腹板剪力分配 \\
\hline 2 & $\begin{array}{l}\text { 纵向: 空间梁单元 } \\
\text { 横向: 框架计算 }\end{array}$ & $\sqrt{ }$ & $\sqrt{ }$ & $\sqrt{ }$ & $x$ & $x$ & $x$ & $\sqrt{ }$ & $x$ \\
\hline 4 & 三维实体单元 & $\sqrt{ }$ & $\sqrt{ }$ & $\sqrt{ }$ & $\sqrt{ }$ & $\sqrt{ }$ & $\sqrt{ }$ & $\sqrt{ }$ & $\sqrt{ }$ \\
\hline
\end{tabular}




\section{5. 箱梁的空间效应}

箱梁的空间效应包括剪力滞效应和畸变效应。

\subsection{1. 剪力滞效应}

剪力滞效应是指宽翼缘箱型截面在对称垂直作用力下, 其上、下翼缘的正应力 沿着宽度方向分布不均匀的现象称为剪力滞效应, 受桥梁的宽跨比, 以及箱梁上翼 缘板承托尺寸等因素影响。这种效应会造成箱梁腹板出的应力水平偏高。如果忽略 这种效应, 就会低估箱梁腹板和翼缘板交接处的应力, 导致实际应力超过设计应力, 造成翼缘板开裂, 影响结构的安全性。对于箱梁的剪力滞效应, 目前规范通过对翼 缘宽度的折减(有效分布宽度)来包络剪力滞效应引起的应力峰值。但有效分布宽度 的确定主要依靠工程经验和近似理论推导, 适用范围有限[12]。对于这种情况, 在 设计时, 通常使腹板的计算应力小于规范规定的最大应力值, 且与规定值保持一定 差距, 必要时应采用三维实体单元法进行分析, 确定剪力滞效应系数, 避免箱梁因 剪力滞效应引起应力超限而开裂。

\subsection{2. 畸变效应}

箱梁的畸变效应是箱梁在反对称荷载作用下，除了截面会产生刚性扭转外，还 会产生周边变形, 即畸变。箱梁畸变是产生翘曲正应力的主要原因, 同时畸变也对 截面的抗扭性能产生不容忽视的影响。对于变截面箱梁的畸变效应较完善的计算理 论是由捷克学者以梁框共同作用原理建立的, 但是该理论求解困难, 难以在实际工 程中推广使用。为便于在实际工程应用, 可以采用等代梁法对变截面箱梁的畸变应 力进行分析, 将箱梁的畸变等效于腹板受顶板、底板约束的坚向挠曲问题 [19], 这 种方法充分考虑变截面箱梁的截面刚度变化对结构内力的影响, 具有受力分析明确, 计算简便, 精度较高的优点。

\section{6. 箱梁的横向分析}

横向分析可以判断整个桥跨范围内箱梁的薄弱断面, 以便采取必要的技术措施, 确保每个断面在荷载作用下横向的安全性, 进而有效控制箱梁的纵向裂缝和混凝土 䢃裂。进行横向分析, 目前主要按照框架模型计算, 需要验算顶板、腹板、底板的 抗裂能力 (如果配置预应力)、裂缝宽度和极限承载能力。由于连续刚构预应力箱梁 实际的受力状态是三维受力状态, 因此, 在计算腹板主拉应力时, 应考虑横向和纵 向的应力叠加效应。

\section{7. 配筋设计}

连续刚构桥的配筋设计包括纵向预应力束的布置, 横向和竖向预应力筋的布置, 以及普通钢筋的配置等内容。其中的纵向预应力束的布置又包括承受负弯矩的顶板 预应力束、承受正弯矩的底板预应力束, 腹板预应力束以及补充使用阶段承受内力 的连续束和合拢段临时束; 横向预应力筋的布置考虑当箱梁顶板宽度较大时, 避免 结构在重力及荷载作用下产生纵向裂缝; 坚向预应力筋的布置则是为了限制腹板主 拉应力，提高腹板的抗裂性。 


\subsection{1. 纵向预应力筋的配置}

沿桥跨方向的纵向预应力筋, 是用以保证桥梁在恒、活载作用下纵向承载能力 和跨越能力的主要受力筋, 布置在顶板、底板之中, 并且上弯或下弯针固在腹板之 内, 设计宜采用大吨位钢绞线, 减少截面上预应力孔道数量, 以降低孔道对截面的 削弱作用。

\subsection{2. 腹板下弯束的配置}

早期建设的连续刚构桥, 为了方便施工, 在布置预应力钢束时取消腹板下弯束 和连续束, 仅依靠坚向预应力和纵向预应力来克服主拉应力。但经过长期的工程实 践, 这种简化预应力钢束的方式使得箱梁腹板上出现斜裂缝的几率大幅度增加, 跨 中下挠程度持续加深[20]。研究表明, 采用腹板下弯束限制主拉应力以及降低腹板 斜裂缝出现的概率是行之有效的办法 [6], 设置腹板下弯束, 不仅能够提供预剪力, 还能减少纵向预应力盲区。虽然布置了腹板下弯束, 仍有一定概率出现腹板斜裂缝, 但这只是表明, 腹板下弯束的布置方式仍有很大的优化空间。

\subsection{3. 坚向预应力束的配置}

在没有设置腹板下弯束的箱梁中, 或腹板中的剪应力或主拉应力较大时, 通过 设置腹板坚向预应力束, 同样可以达到改善腹板主拉应力, 提供预剪力, 提高腹板 抗裂性的作用。坚向预应力筋一般下端埋入腹板混凝土, 上端针固在顶板顶面。但 是从实际工程来看, 由于存在以下几点问题[21], 使得设置坚向预应力钢束完全替 代腹板下弯束的效果并不良好:

1) 竖向预应力筋长度较短, 预应力损失大;

2) 坚向预应力针固张拉施工随意性大，精度不易保证;

3) 坚向预应力孔道狭窄, 压浆质量不易保证, 导致截面削弱。

以上几方面的因素导致箱梁坚向压应力不够, 克服主拉应力的能力不足, 使腹 板出现腹板斜截面开裂, 从而使结构刚度降低, 引起主梁跨中下挠增加[22]。因此, 以坚向预应力束完全取代腹板下弯束的效果还不够理想, 有待进一步的研究。

\subsection{4. 横向预应力束的配置}

横向预应力束的作用是保证桥梁的横向整体性, 以及作为桥面板横向抗弯能力 的主要受力筋。一般布置在顶板之中。当腹板间距较大, 如果不设置横向预应力束, 顶板的易产生纵向裂缝, 根据我国的工程经验, 当顶板宽度大于 $9 \mathrm{~m}$ 时, 应设置横 向预应力束。横向预应力束一般为直线型, 布置在顶板的上、下两层钢筋网之间, 针固于悬臂板末端。

\subsection{5. 普通钢筋的布置}

在预应力混凝土连续刚构桥中, 除了合理配置预应力束外, 根据《公路钢筋混 凝土及预应力混凝土桥梁设计规范》(JTG D62-2004)的规定, 应在合适的位置配置 数量合适的普通钢筋, 钢筋种类包括箍筋、水平分布钢筋、纵向分布钢筋、架立钢 筋等。在预应力混凝土刚构桥中, 普通钢筋的作用[23]包括:

1) 控制收缩徐变和温差引起的裂缝;

2) 承受施工阶段拉应力; 
3) 加强针固区;

4) 防止局部崩裂;

5) 提高箱梁的抗剪承载力。

\section{8. 桥墩设计}

\subsection{1. 高墩的抗震性能分析}

山区连续刚构桥多具有高桥墩的特点。高墩墩柱的长细比和轴压比通常较大, 且多为空心截面。对于高墩连续刚构桥, 下部结构自重比重上升, 不可仿照中、低 墩连续刚构桥将结构等效为单自由度体系进行计算, 对于高墩连续刚构桥, 高阶振 型的效应和自身质量对地震响应的贡献将比中、低墩刚构桥明显。我国现行的公路 桥梁抗震设计规范仅仅适用于主跨不超过 $150 \mathrm{~m}$, 墩高不超过 $40 \mathrm{~m}$ 的桥梁, 对于墩 高超过 $40 \mathrm{~m}$ 、墩身一阶振型有效质量低于 $60 \%$, 结构进入弹塑性工作范围的桥梁 则需要进行专门的抗震研究[24]。高墩在地震中的响应具有以下特征[25]:

1) 坏多发生在桥墩根部，墩顶位移最大;

2) 高墩的横向地震反应比纵向大;

3) 在高墩的延性性能方面, 单柱式桥墩比双柱式桥墩的墩顶位移大。

为评估地震对桥梁的破坏, 可采用地震易损性分析方法, 这种方法可以反映在 不同强度的地震作用下，结构超过规定破坏极限状态的概率。对于高墩大跨径连续 刚构桥宜采用时程分析以考虑结构非线性的影响, 以墩的位移延性比和材料的应力 应变作为评价地震损伤的指标。

\subsection{2. 桥墩的施工稳定性分析}

山区大跨度连续刚构桥为了有效减少结构的内力、减少混凝土收缩徐变、温度 及地震的影响, 往往采用高大的柔性墩设计, 这样就首先要考虑在悬臂施工工程中 的桥墩的稳定性问题。桥墩的稳定问题可分为两类, 第一类稳定问题为结构分支点 失稳，只考虑材料为理想的线弹性体，不考虑各种非线性的影响; 第二类稳定问题 为极值点失稳, 即结构保持原有的平衡状态不变, 当外力达到临界值时, 结构的变 形迅速增大而丧失稳定的情况[26]。实际工程中的失稳都属于第二类稳定问题。对 于单肢薄壁墩的稳定问题，可直接运用压杆稳定的理论公式进行计算；而对于双肢 薄壁空心墩的稳定问题, 需要进行常截面单墩自重作用下的稳定性计算、单薄壁墩 悬浇阶段稳定性计算、双肢墩悬浇阶段面内稳定性分析, 通常采用有限元程序计算。 在初步设计时，可参考文献[6]的简化算法进行稳定性的估算。

\section{9. 桥梁结构的耐久性设计}

\subsection{1. 耐久性设计的重要意义}

桥梁工程未来发展的主导方向之一是耐久性的研究，桥梁全寿命设计理论的提 出也是基于耐久性的考虑, 这一理论不但考虑当前需要, 又要考虑未来发展需要; 既要考虑成桥时的性能, 又要考虑运营阶段的性能变化; 不只着眼当前的利益, 又 要考虑长远存在的风险。从可行性研究到桥梁拆除回收, 贯穿整个桥梁的生命历程, 以结构可检修、构件可更换、病害可控制、性能可恢复、全桥寿命可持续为设计出 发点, 使桥梁有更大的保证率让使用寿命达到设计预期。 


\subsection{2. 我国桥梁耐久性研究的现状}

目前我国的桥梁设计规范均按照 “承载能力极限状态” 和 “正常使用极限状态” 两种状态进行设计验算, 但通过一些桥梁病害与事故反映, 有的桥梁因为耐久性不 佳而使抗力下降使得桥梁使用寿命缩短的现象, 并不都在这两种极限状态内。这从 侧面反映出我国现行的桥梁设计理念和桥梁规范存在考虑不周全的地方。目前的设 计理论多注重结构的承载能力和使用功能, 对于运营阶段桥梁品质应内外因素的影 响的变化, 基本没有去考虑, 85 规范对使用寿命和耐久性指标的规定基本是空白的, 04 规范虽然规定了设计基准期和混凝土耐久性指标, 但是过于简单, 具体实施起来 困难较大 [27]。最新的 15 规范中, 明确地提出了桥梁设计使用年限和耐久性的相关 概念以及相关的设计要求, 在作用计算中还增设了 “设计使用年限荷载调整系数” 来检验运营阶段桥梁品质的变化情况。对于我国桥梁耐久性研究来说, 这无疑是一 次巨大的进步, 但因为颁布时间不久, 尚未有按新规范建设的桥梁投入使用, 具体 效果还有待历史的检验。

\section{5. 施工关键技术及施工控制}

\section{1. 施工方法及设备}

大跨径连续刚构桥的施工方法目前主要采用的是悬臂浇筑施工方法。该方法是 将梁体沿桥梁轴线分成若干节段, 在桥墩两侧设置工作平台, 平衡地逐段向跨中悬 臂浇筑混凝土梁体, 并逐段施加预应力的方法。悬臂浇筑时, 全桥一般分为墩顶梁 段、对称悬臂浇筑段、边跨现浇段、合龙段四大部分。墩顶梁段通常称为 0 号块, 长度不宜过大, 但因有足够的长度拼装挂篮; 对称悬浇梁段长度一般为 $2 \sim 5 \mathrm{~m}$, 边 跨现浇段一般为 $2 \sim 3$ 个悬浇分段长度; 合龙段长度一般为 $1 \sim 3 \mathrm{~m}$ [28]。图 4 是连 续刚构桥悬臂浇筑流程图。

\subsection{1. 悬臂施工法的优点}

悬臂浇筑施工方法具有施工设备少, 周转材料需求少, 除边跨现浇段以外, 无 需搭设落地支架, 无需大型的起吊、运输设备, 施工场地需求小等特点。

\subsection{2. 主要施工设备}

该方法的主要施工设备是一对能行走的挂篮, 对于挂篮的要求是挂篮自重轻, 结构简单, 受力明确, 移运方便, 并要求坚固稳定, 变形小, 便于针固、拆装, 尽 量利用现有构件。挂篮的主要形式有三角形、菱形、平行桁架式、平弦无平衡重式、 弓弦式等, 由于三角形及菱形挂篮具有结构简单、受力明确、装拆便捷、行走灵活 等优势目前与取代其他几种挂篮, 成为主要的挂篮形式。

\section{2. 施工关键技术}

\subsubsection{0 号块的施工}

墩顶 0 号梁段结构复杂, 全桥纵向预应力钢束均通过此处, 受力复杂, 体积大, 混凝土用量大, 施工难度大, 是连续刚构桥施工的重点难点。高墩大跨连续刚构桥 的 0 号梁段通常在墩旁托架上施工, 安装模板前必须进行预压, 消除托架下沉变形 的影响; 模板安装要根据设计高程进行准确定位, 钢筋安装时要确保预应力管道的 


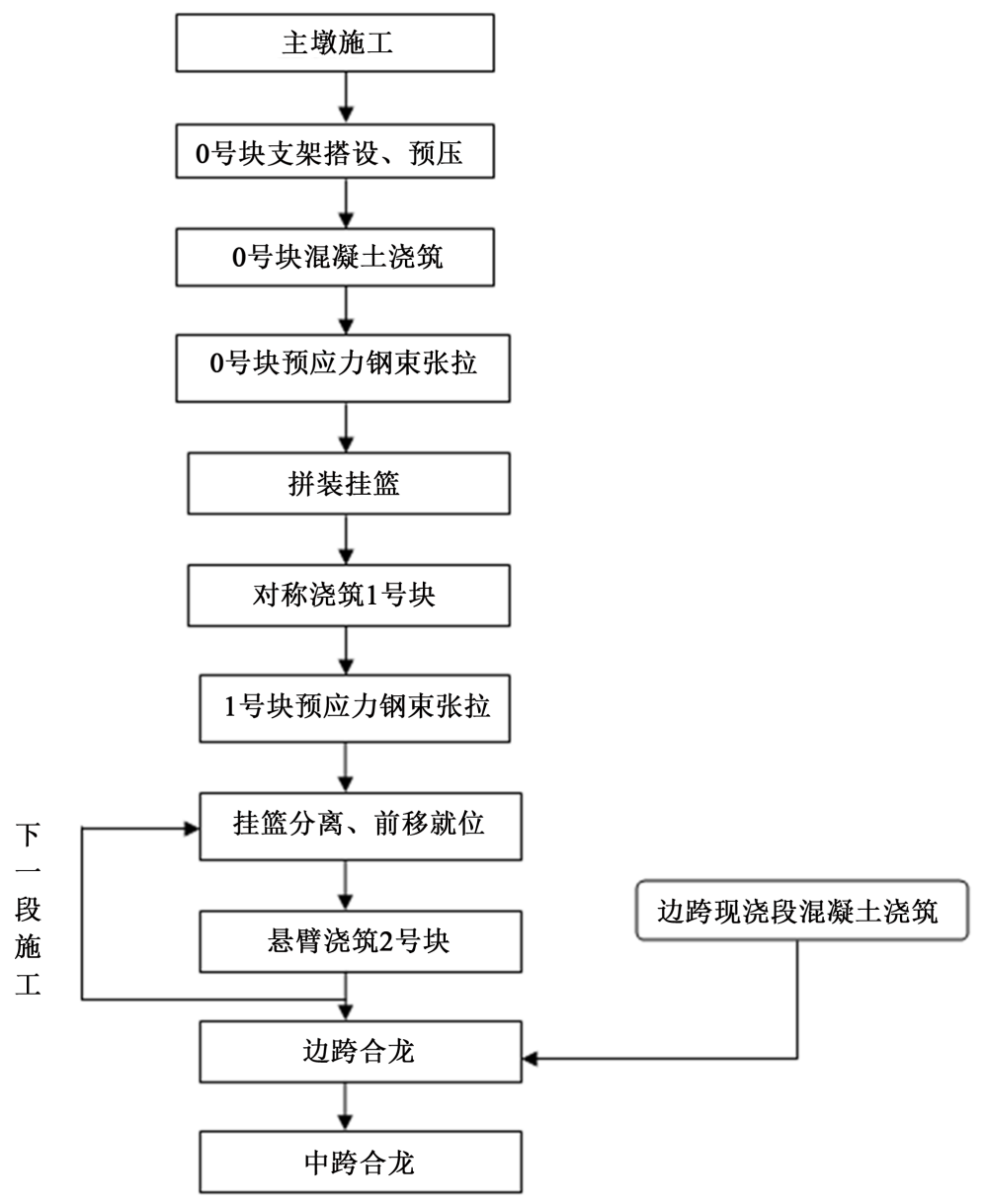

图 4. 连续刚构桥悬臂浇筑流程图

准确定位。0 号梁段的混凝土通常采用全断面一次浇筑成型, 如果因为梁高、混凝 土数量大等原因, 考虑浇筑时间长以及水化热大等情况, 可以采取分层浇筑, 优选 原料, 合理添加缓凝剂, 控制入模温度和在低温时段进行浇筑等措施来达到控制水 化热, 避免温度裂缝。每层浇筑间隔时间不宜超过 7 天, 新旧混凝土结合面应丵毛 并清洗干净。浇筑顺序是先底板, 后腹板, 最后顶板。混凝土要进行不少于 7 天的 保湿养护, 强度达到设计要求时, 可张拉预应力钢束。张拉时采用对称张拉, 遵循 “先纵、后坚、再横向”, “先长后短”, “先中间, 后两边” 的顺序。张拉完成 后应及时进行压浆, 防止预应力钢束的锈蚀。

\subsection{2. 悬浇段施工}

\section{(1) 挂篮拼装及预压}

0 号块施工完成后, 在该梁段顶面进行挂篮拼装, 挂篮在运至现场之前, 应在 制作厂进行预拼装, 以便发现问题并及时解决。拼装挂篮时, 应严格控制场地平整, 避免挂篮存在安装误差。安装完成后, 必须对挂篮进行预压。通过预压, 可以检验 挂篮的实际承载能力和可靠性, 消除挂篮的非弹性变形; 通过分级加载, 可以掌握 挂篮的变形规律, 获得挂篮的弹性变形数据, 为悬浇施工的线型控制提供可靠依据 [28]。常用的预压方法有：堆载预压法、水箱预压法和反力架预压法。每种方式各 
有优势, 应根据施工单位现有设备和施工环境进行选择。

\section{(2) 悬臂浇筑注意事项}

悬浇段施工作为悬臂浇筑法的核心环节, 其施工质量直接决定了连续刚构桥成 桥后的线型质量和工程质量。在悬臂浇筑过程中应注意以下几点:

1) 模板安装应根据预压结果核准核心位置, 调整高程。

2) 悬臂浇筑应两侧对称、平衡浇筑。当无法避免不平衡荷载时, 应严格控制不 平衡荷载不超过设计规定。当没有规定时, 不平衡荷载不应超过 $1 / 4$ 浇筑梁段重量。

以避免挂篮偏载过大和模板移位。

3) 浇筑顺序为从挂篮前端向后端浇筑。时挂篮变形尽早出现, 保证接触面混凝 土浇筑质量。

4) 浇筑过程中应对实际高程进行监控, 并根据设计控制值及时调整。

\subsection{3. 合龙段施工}

\section{(1) 合龙方式的选择}

连续刚构桥悬臂浇筑到最大悬臂状态构成多个 $T$ 构, 将这些 $T$ 构拼接成整体, 就是合龙。连续刚构桥具有多种合龙顺序, 不同的合龙顺序, 引起的结构荷载内力 不同, 对成桥后结果的最终恒载内力也不同, 设计和施工时应给予充分考虑:

1) 从桥梁一端到另一端顺序浇筑合龙: 这种方法施工方便, 成桥前稳定性和刚 度较强, 但作业面长, 施工工期长, 该方法主要适用于多跨长桥;

2) 先边跨后中跨合龙: 这种方法施工进度快, 可以缩短工期, 是 3 5 跨连续 刚构桥常用的施工方法;

3) 先中跨后边跨合龙: 这种方法对于结构受力分析有利, 特别是对收缩徐变产 生的次内力控制较好, 但是成桥前悬臂时间长, 稳定性差, 抗风能力较差, 在山区 风向复杂地区要谨慎使用;

4) 多孔一次性合龙: 虽然在理论受力合理, 但是由于各 $T$ 构龄期不同以及混凝 土的不均匀性、施工偏差等影响, 可能存在难以估计的薄弱环节, 对工程安全性存 在隐患, 而且施工设备投入多, 经济性较差。

\section{(2) 合龙段施工的要点}

合龙段施工是连续刚构桥的结构体系由悬臂静定结构转换为超静定连续结构的 体系转换过程。施工时应该注意以下要点:

1) 应编制详细的工艺流程和施工方案确保合龙段施工后全桥满足受力状态、梁 体线型的设计要求;

2) 根据结构情况和温度情况, 选择合适的合龙方式并进行力学验算;

3) 合龙段长度在不影响施工操作的前提下, 应该尽可能的短, 一般采用 $1.0 \sim 3.0 \mathrm{~m}$;

4) 合龙时间选择在温度低、温差小的时段进行, 并且在温度开始升高前完成合 龙; 为保持稳定，合龙口在浇筑混凝土前应进行锁定;

5) 浇筑混凝土时, 应在悬臂端进行平衡配重, 浇筑用混凝土宜比梁体高一个等 级;

6) 为消除合龙温差引起的墩顶水平位移和结构附加的温度应力, 可经设计计算 
后, 采用顶推法进行合龙段施工[28]。即在合龙段施加一对顶力, 强迫墩顶发生位 移, 使墩顶初位移接近于零。

\subsection{4. 高墩施工}

\section{(1) 高墩施工方法}

山区连续刚构桥桥墩高度普遍较高, 高墩的施工技术也是全桥施工中的重点难 点, 针对空心薄壁高墩, 目前常用的有三种施工方法: 滑模施工、爬模施工、翻模 施工。滑模施工在施工中必须是动态连续, 不能间断的, 而且模板结构复杂, 设备 投入大, 成本较高; 爬模施工的模板结构复杂, 预埋件定位要求高, 浇筑的混凝土 整体性较差, 外观质量差; 翻模施工进度快, 结构整体性好, 混凝土浇筑质量好, 且模板定位简单可靠, 具有良好的经济性和适用性。在浇注墩身混凝土时, 应沿墩 身坚向分层循环浇筑。

\section{(2) 泵送混凝土防堵管措施}

浇筑高墩的混凝土，就涉及到对衼送混凝土堵管问题的防治。相关工程资料表 明, 选择低温环境下, 设置合适的长度水平管道和弯管, 充分润滑管壁, 合理使用 减水剂等措施对预防混凝土堵管是科学有效的[29]。

\subsection{5. 施工质量对梁体下挠的影响}

跨中梁体下挠严重一直是困扰连续刚构桥的问题之一, 究其原因在于以下几点: 悬臂浇筑梁段时采用设置预拱度的形式消除梁体下挠, 这是被动的、不充分的, 设 置预拱度虽然可以抵消部分弹性下挠, 但是对于徐变下挠的效果甚微[6]; 梁体轻型 化造成的徐变系数的增大, 引起徐变下挠的严重程度和持续时间加深; 梁体浇筑时 对于超重控制不佳; 为缩短工期, 在混凝土弹性模量没有达到一定程度时过早施加 预应力, 造成弹性挠度和徐变挠度的增加; 预应力管道施工质量不佳, 引起实际预 应力损失超过设计值，导致梁体下挠。总的来说，在施工中控制梁体下挠，要正确 认识混凝土徐变作用的影响, 探索更积极主动的方式, 合理设置加载龄期, 以及应 用先进的预应力管道的施工工艺，以消除在施工过程中导致梁体下挠的隐患。

\section{3. 施工监控控制}

\subsection{1. 施工监控控制的必要性}

桥梁施工控制是确保桥梁施工质量的关键，同时也是保障桥梁建设安全进行的 安全系统。大跨径连续刚构桥采用悬臂施工方法架设, 受外界环境影响以及混凝土 材料特性的影响, 各节段之间必定存在差异并相互影响, 这必然造成各节段的内力 和位移随施工过程变化而偏离设计值的现象 [30], 为了使成桥状态的几何线形和受 力状态符合设计要求, 确保施工过程中刚构桥的可靠度和安全性, 必须进行有效的 施工监控, 做到及时发现, 及时调整。大跨径连续刚构桥的施工控制包括变形和内 力控制。同时由于超静定结构对温度和变形敏感的特点, 因此对温度和周围环境的 监测也是必要的。

\subsection{2. 施工控制中的结构分析方法}

对于大跨径连续刚构桥的施工控制方法是预测控制法，即首先理论计算确定控 
制目标, 然后在施工现场跟踪实际操作保证目标得以实现。施工控制的一项最基本 的内容就是对施工各个阶段进行详细的变形计算和受力分析。采用前进分析法可以 得到桥梁结构各施工阶段的位移和内力状态, 为保证结构强度、刚度提供依据; 采 用后退分析法则可以确定各施工阶段的理想的安装位置和理想的内力状态。总的来 说, 对于大跨度连续刚构桥的施工控制遵循 “施工 - 量测 - 识别 - 修正 - 预测 - 施 工” [31]的过程, 目的是使施工按照设计要求进行。

\subsection{3. 线形控制方法及不足}

线形控制是作为连续刚构桥施工控制中一个重要环节。线形控制的好坏是保证 成桥状态是否符合设计要求、行车是否平顺的重要因素。对于连续刚构桥来说, 存 在三种线形变化, 一是施工中由于分段悬臂浇筑、张拉预应力、桥面铺装引起的变 形; 二是成桥后收缩徐变引起的变形; 三是桥梁运营中在活载作用下产生的变形。 对于连续刚构桥的线形控制存在以下难点:

1) 混凝土材料存在变异性;

2) 混凝土的收缩徐变和预应力损失难以准确计算;

3) 非线性因素以及施工误差的影响。

设置预拱度是目前国内在连续刚构桥上普遍采用的线形控制方法。参考铁路桥 涵的设计规范, 成桥预拱度的取值采用考虑收缩徐变的恒载挠度值与 0.5 倍活 载挠度值之和。采用该方法确定预拱度存在几点不足[32]:

1) 没有改变成桥后的内力状态, 不能减少混凝土长期收缩徐变变形;

2) 长期收缩徐变变形难以计算准确, 恒载挠度预拱度取值难以确定;

3) 实际工程中预拱度宁高冊低, 造成成桥高程偏离设计高程较大;

4) 对于单向纵坡桥梁, 预拱度过大, 改变坚曲线形状, 影响行车速度和舒适性。 总的来说，采用设置预拱度的方式控制连续刚构桥的线形是一种被动的控制方 法。根据文献[33] [34], 一种基于林同炎先生提出的荷载平衡理论主动进行线形控 制的方法, 经过理论分析与数值模拟, 已取得比较好的效果。但是应用到实际工程 中, 还有点进一步的深入研究。

\subsection{4. 卡尔曼滤波法及灰色理论的应用}

连续刚构桥主要依靠本阶段的施工数据对下阶段的施工进行预测控制, 采用卡 尔曼滤波法, 不但可以对刚构桥的内力和变形进行控制, 还能较正确的对下一阶段 结构的状态进行预测, 是一个相当有效的施工控制和调整方法, 这一方法在大跨度 连续刚构桥施工建设这一系统工程中获得广泛采用。但是卡尔曼滤波法的局限性在 于当每个施工阶段得到观测数据量较小时, 该方法的精度就会受到影响。当观测数 据量较少的情况下, 可以采用灰色系统理论对于数据进行处理, 利用较少的数据建 立关联度较高, 精确度较高的预测模型, 是该方法的一大特点。目前对于该方法在 大跨度连续刚构桥上的应用还处于起步阶段, 随着研究的深入, 灰色系统理论一定 能更好的服务于连续刚构桥的施工监控中。

\section{6. 连续刚构桥的发展与展望}

连续刚构桥由于结构整体性好, 跨越能力强, 设计理论完善, 施工工艺成熟, 
经济指标优良等特点, 在贵州山区地区发展迅速。主跨径 $290 \mathrm{~m}$ 的水盘公路北盘江 大桥, 开创了新型空腹式连续刚构桥体系[35]以及拥有亚洲第一高墩的毕威高速赫 章大桥的建成通车, 标志着我省的连续刚构桥建设水平已达到国内乃至世界先进水 平。随着材料、设备、工艺的不断创新, 连续刚构桥将成为山区跨越大河深沟的主 要梁桥形式, 施工难度比同等跨径的拱桥低、经济性又优于混凝土斜拉桥, 连续刚 构桥的前景将是十分广阔。可以期待的是, 随着混凝土材料的发展和新型结构形式 的研究应用, 在不远的将来, 连续刚构桥的可行跨径将很有可能突破 $350 \mathrm{~m}$, 甚至 更大。这不但可以填补连续刚构桥与斜拉桥之间适用跨径的空白, 还可能在更大跨 径范围内, 成为预应力混凝土斜拉桥的强有力的竞争者。展望未来, 连续刚构桥的 发展将依托上部结构轻型化, 应用超高强度混凝土, 组合结构和新型结构的研究和 应用，朝着 “大跨径，高强度，耐久优” 的方向发展。

\section{References}

[1] 余远程, 李银斌. 贵州省山区公路连续钢构桥梁特点分析及应用[J]. 公路交通科技: 应 用技术版, 2009(9): 108-110.

[2] 罗松涛, 黄才良, 荆友璋. 不对称连续刚构的不对称系数[J]. 公路交通科技, 2012, 29(4): 62-66.

[3] 刘效尧, 徐岳. 公路桥涵设计手册. 梁桥[M]. 北京: 人民交通出版社, 2011.

[4] 姜友生. 桥梁总体设计 [M]. 北京: 人民交通出版社, 2012.

[5] 龙佩恒, 刘靖, 张文学, 等. PC 连续刚构桥梁底合理曲线线形研究 [J]. 石家庄铁道大学 学报(自然科学版), 2011, 24(2): 28-32.

[6] 彭元诚. 山区大跨度连续刚构桥[M]. 北京: 人民交通出版社, 2015 .

[7] 徐超. 大跨高墩连续刚构桥桥墩结构型式研究[D]: [硕士学位论文]. 重庆: 重庆交通大 学, 2014.

[8] 廖朝华. 公路桥涵设计手册[M]. 北京: 人民交通出版社, 2013.

[9] 邵旭东, 詹豪, 雷薇, 张哲. 超大跨径单向预应力 UHPC 连续箱梁桥概念设计与初步实 验[J]. 土木工程学报, 2013(8): 83-89.

[10] 陈增林. 结构用轻骨料混凝土 [M]. 长沙: 湖南科学技术出版社, 1982.

[11] 刘数华, 阎培渝. 高性能轻骨料混凝土在桥梁工程中应用的研究进展[J]. 公路, 2006(8): 176-180.

[12] 徐栋, 赵瑜, 刘超. 混凝土桥梁结构实用精细化分析与配筋设计(精) [M]. 北京: 人民交 通出版社, 2013.

[13] 张阳, 郡旭东, 李斌. 二次张拉钢绞线箱梁腹板坚向预应力损失研究 [J]. 湖南大学学报: 自然科学版, 2012, 39(6): 13-18.

[14] 马建, 孙守增, 杨琦, 等. 中国桥梁工程学术研究综述·2014[J]. 中国公路学报, 2014, 27(5): 1-96.

[15] 马保林. 高墩大跨连续刚构桥 [M]. 北京: 人民交通出版社, 2001.

[16] 邵旭东, 程翔云. 桥梁设计与计算(精) [M]. 北京: 人民交通出版社, 2012.

[17] 袁立. 风力作用对高墩大跨连续刚构桥结构影响 [C]//贵州省交通运输厅. 山区高速公路 连续刚构桥桥梁建设与管理论文集. 北京: 人民交通出版社, 2012: 60-67.

[18] 彭元诚. 大跨径连续刚构桥风振分析 [C]//贵州省交通运输厅. 山区高速公路连续刚构桥 桥梁建设与管理论文集. 北京: 人民交通出版社, 2012: 42-50. 
[19] 郭金琼, 詹开火. 等代梁法分析变截面箱形梁畸变应力[J]. 第一次城市桥梁学术会, 2007: 600-605.

[20] 范立础. 预应力混凝土连续梁桥 $[\mathrm{M}]$. 北京: 人民交通出版社, 2001.

[21] 何飞. 高墩大跨预应力混凝土连续刚构桥运营期间主要病害成因分析及其健康监测内 容研究 $[\mathrm{C}] / /$ 贵州省交通运输厅. 山区高速公路连续刚构桥桥梁建设与管理论文集. 北 京: 人民交通出版社, 2012: 88-95.

[22] 于天来, 姜震. 连续刚构箱梁桥腹板开裂原因分析[J]. 中外公路, 2013, 33(2): 132-136.

[23] 姚玲森. 桥梁工程[M]. 北京: 人民交通出版社, 2013.

[24] 重庆交通科研设计院. JTG/TB02-01-2008 公路桥梁抗震设计细则[S]. 北京: 人民交通出 版社, 2008.

[25] 范立础. 桥梁抗震 $[M]$. 上海: 同济大学出版社, 1997.

[26] 蒙昊. 预应力混凝土连续刚构桥的概念设计 [D]: [硕士学位论文]. 成都: 西南交通大学, 2013.

[27] 严允中, 杨虎根, 许伟, 曾爱. 上承式混凝土拱桥建造实例及评析 $[M]$. 北京: 人民交通 出版社, 2015.

[28] 中交第二公路工程局有限公司. 公路桥梁施工系列手册 [M]. 北京: 人民交通出版社, 2014.

[29] 田汉丰. 空心薄壁高墩混凝土现场施工洜送技术 $[C] / /$ 贵州省交通运输厅. 山区高速公路 连续刚构桥梁建设与管理论文集. 北京: 人民交通出版社, 2012: 279-283.

[30] 向中富. 桥梁工程控制[M]. 北京: 人民交通出版社, 2011.

[31] 徐君兰. 大跨度桥梁施工控制 $[\mathrm{M}]$. 北京: 人民交通出版社, 2000 .

[32] 何天涛. 大跨径预应力混凝土梁桥挠度研究[D]: [硕士学位论文]. 长沙: 长沙理工大学, 2008.

[33] 姚强. 基于荷载平衡法的大跨径 PC 连续刚构桥长期挠度控制方法研究[D]: [硕士学位论 文]. 西安: 长安大学, 2009.

[34] 侯安. 连续刚构桥裂缝防治及预拱度优化研究[D]: [硕士学位论文]. 长沙: 长沙理工大 学, 2009.

[35] 彭元诚, 汪金育, 梅世龙, 等. 空腹式连续刚构桥关键技术 [C]//中国交通建设股份有限 公司. 中国交通建设股份有限公司 2012 年现场技术交流会. 2012: 8-18.

\section{Submit or recommend next manuscript to OALib Journal and we will provide best service for you:}

- Publication frequency: Monthly

- 9 subject areas of science, technology and medicine

- Fair and rigorous peer-review system

- Fast publication process

- Article promotion in various social networking sites (LinkedIn, Facebook, Twitter, etc.)

- Maximum dissemination of your research work

Submit Your Paper Online: Click Here to Submit

Or Contact service@oalib.com 